\title{
Racial and Ethnic Group Variations in Service Use in a National Sample of Medicare Home Health Care Patients with Type 2 Diabetes Mellitus
}

Amoah Yeboah-Korang

University of Connecticut School of Medicine and Dentistry

Alison Kleppinger

University of Connecticut School of Medicine and Dentistry

Richard H. Fortinsky

University of Connecticut School of Medicine and Dentistry

Follow this and additional works at: https://opencommons.uconn.edu/uchcres_articles

\section{Recommended Citation}

Yeboah-Korang, Amoah; Kleppinger, Alison; and Fortinsky, Richard H., "Racial and Ethnic Group Variations in Service Use in a National Sample of Medicare Home Health Care Patients with Type 2 Diabetes Mellitus" (2011). UCHC Articles - Research. 58.

https://opencommons.uconn.edu/uchcres_articles/58 


\title{
Racial and Ethnic Group Variations in Service Use in a National Sample of Medicare Home Health Care Patients with Type 2 Diabetes Mellitus
}

\author{
Amoah Yeboah-Korang, BS ${ }^{*}$, Alison Kleppinger, MS $^{\dagger}$, and Richard H. Fortinsky, PhD $^{\dagger}$ \\ "School of Medicine, University of Connecticut, Farmington, Connecticut \\ † UConn Center on Aging, University of Connecticut Health Center, Farmington, Connecticut
}

\begin{abstract}
Type 2 diabetes mellitus is known to affect adults in racial and ethnic minority groups disproportionately. When diabetes mellitus-related symptoms lead to the need for skilled care in the community-dwelling Medicare population, physicians can order the Medicare home health care (HHC) benefit, and Medicare-certified home health agencies can deliver it. Little is known about the extent to which racial and ethnic disparities exist in types and patterns of HHC services delivered to Medicare beneficiaries with diabetes mellitus when they are approved for the Medicare HHC benefit. This was examined by comparing racial and ethnic groups in terms of measures of $\mathrm{HHC}$ service use in a nationally representative sample of Medicare $\mathrm{HHC}$ beneficiaries with a primary diagnosis of type 2 diabetes mellitus. Uniform clinical data from the Outcome and Assessment Information Set were linked with Medicare HHC claims for beneficiaries who received a complete episode of $\mathrm{HHC}$ in 2002. In the study sample $(\mathrm{n}=9,838), 62 \%$ of participants self-identified as white, 22\% African American, 12\% Hispanic, and 3\% Asian. Nearly all (99\%) participants in all racial and ethnic groups received skilled nursing services. Controlling for numerous sociodemographic and health-related covariates and geographic region of the country, African-American participants received fewer nurse visits per week and fewer visits per week from all clinical disciplines combined than whites (both $P<.001$ ), and Hispanic participants were less likely than whites to receive physical therapy (adjusted odds ratio (AOR) $=0.640,95 \%$ confidence interval $(\mathrm{CI})=0.543-0.754, P<.001)$ or home health aide $(\mathrm{AOR}=0.716,95 \% \mathrm{CI}=$ $0.582-0.880, P<.002$ ) services. Lower use of skilled nursing and rehabilitation services by African Americans and of rehabilitation services by Hispanics warrant further clinical and research attention.
\end{abstract}

\section{Keywords}

health disparities; Medicare home care; diabetes mellitus care

(C) 2011, Copyright the Authors

Address correspondence to Richard H. Fortinsky, UConn Center on Aging, University of Connecticut Health Center, 263 Farmington Avenue, Farmington, CT 06030. fortinsky@uchc.edu.

Portions of this article were presented at the 2009 Annual Meeting of the American Geriatrics Society and at the 2009 Annual Meeting of the American Public Health Association.

Conflict of Interest: The editor in chief has reviewed the conflict of interest checklist provided by the authors and has determined that the authors have no financial or any other kind of personal conflicts with this paper.

Author Contributions: AYK: study concept and design, analysis and interpretation of data, preparation of manuscript. AK: analysis and interpretation of data, preparation of manuscript. RHF: study concept and design, acquisition of data, analysis and interpretation of data, preparation of manuscript. 
Type 2 diabetes mellitus is a chronic disease that disproportionately affects racial and ethnic minority populations. Racial and ethnic minorities experience a greater prevalence of diabetes mellitus and diabetes mellitus-related complications, poorer health outcomes, and higher Medicare expenditures than whites. ${ }^{1-13}$ An important healthcare setting in which a great amount of diabetes mellitus care is provided to Medicare beneficiaries, but where little is known regarding racial and ethnic patterns of care, is home health care (HHC). The Medicare HHC benefit offers care provided by nurses, rehabilitation therapists, and nursesupervised home health aides (HHAs). Eligible beneficiaries must require skilled, intermittent care, and a physician must provide prior authorization. Eligible beneficiaries may receive 60 days of $\mathrm{HHC}$ care before recertification is required, offering considerable time to treat and educate them.

Among Medicare HHC beneficiaries, diabetes mellitus is an independent risk factor for subsequent acute care hospitalization. ${ }^{14}$ To help avoid hospitalization, nurses perform skilled tasks, including medication review, blood glucose monitoring, diet and exercise counseling, foot examinations, renal evaluations, and skin care. ${ }^{15} \mathrm{HHAs}$ help beneficiaries perform activities of daily living and with proper training provide basic hygiene and dietary instructions to those with diabetes mellitus. ${ }^{16}$ Older people with diabetes mellitus with limited joint mobility and other musculoskeletal problems due to sedentary lifestyles and weight control problems can receive rehabilitation therapy.

Despite these clinically apparent benefits of Medicare HHC services, little is known about how home health agencies develop care plans and deliver services to people with diabetes mellitus. Moreover, considering the disproportionate diabetes mellitus disease burden in racial and ethnic minorities, surprisingly little is known about types and patterns of HHC services provided to beneficiaries from different racial and ethnic groups once they are deemed eligible to receive Medicare HHC. Therefore, the study reported here was designed to explore types and patterns of Medicare HHC services received by people with diabetes mellitus from different racial and ethnic backgrounds once they were approved for treatment. Specific research questions were: How do African-American, Asian, Hispanic, and white Medicare HHC people with diabetes mellitus compare in the amount of nursing care received? How do these beneficiaries compare regarding whether they receive any physical therapy (PT) and, if so, the amount of PT received? How do these beneficiaries compare regarding whether they receive any HHA care and, if so, the amount of HHA care received? How do these beneficiaries compare in the amount of care received from all clinicians combined (including occupational therapy, speech therapy, and medical social work)?

\section{METHODS}

\section{Design}

Based on a parent study, the present study employed a retrospective cohort design. Major aims of the parent study were to determine factors at Medicare HHC admission associated with hospitalization, change in functional status, and change in symptom severity in a nationally representative sample of Medicare HHC beneficiaries during 2002, the first full year in which all Medicare-certified home health agencies were paid under the current HHC Prospective Payment System (PPS). The institutional review board at the University of Connecticut Health Center approved the parent study protocol, and a Data Use Agreement with the Centers for Medicare and Medicaid Services (CMS) enabled acquisition of data files. 


\section{Data Sources and Study Cohort Construction}

In the parent study, a national cohort was constructed by linking data from the Outcome and Assessment Information Set (OASIS), the Medicare Provider of Services (POS) file, and the Area Resource File (ARF). Medicare HHC claims data were then linked at the person level to build service use measures.

Three steps were accomplished to construct the parent study cohort. First, all Medicarecertified agencies from the Medicare POS file were grouped into 16 strata based on geographic region of the agency's location (northeast, midwest, south, and west), metropolitan or nonmetropolitan location of agency, and free-standing or hospital-affiliation. These stratification variables were chosen because they were found to influence variations in Medicare HHC access and utilization rates. ${ }^{17-21}$

Second, after acquiring all OASIS forms submitted to CMS in 2002, an algorithm was developed to exclude ineligible OASIS forms and then to aggregate all eligible OASIS forms into unique beneficiaries and unique Medicare HHC episodes for each beneficiary. Ineligible OASIS forms included those coded with non-Medicare payment sources and with start-of-care dates before 2002. A CMS staff member with extensive OASIS data experience reviewed and approved the complete algorithm; details were available from the corresponding author. This step yielded 1,870,615 unduplicated Medicare beneficiaries with one or more complete episodes of HHC. For beneficiaries with more than one episode, the first episode was selected for study inclusion.

Finally, these unduplicated beneficiaries were grouped into the 16 strata, then $20 \%$ of beneficiaries within each stratum were randomly selected, yielding a self-weighted, nationally representative $20 \%$ stratified random sample of all beneficiaries with a complete Medicare HHC episode in 2002 for the parent study $(\mathrm{N}=374,123)$.

For the present study, beneficiaries from this parent study sample with a primary home care diagnosis of type 2 diabetes mellitus (International Classification of Diseases, Ninth Revision (ICD-9) codes 250.00 and 250.02) on their Start of Care (SOC) OASIS form and who self-reported as African American, Asian, Hispanic, or white (other groups were too small) were selected, yielding 9,838 participants.

\section{Conceptual Framework and Independent Variable Measurement}

Independent variables were organized into predisposing, enabling, need, and environmental variables, according to the Andersen Behavioral Model of Health Service Use. ${ }^{22}$ The SOC OASIS form was the data source for predisposing, enabling, and need variables; trained clinicians complete this form during the initial home visit. Adequate reliability was reported for most OASIS items contributing to health-related measures used in this study, ${ }^{23}$ functional and cognitive status items were found to have acceptable validity compared with well-established measures. ${ }^{24}$

Predisposing Variables-Racial and ethnic group membership was based on participant-reported self-identification. An important limitation of the OASIS form is that race (e.g., African American) and ethnicity (e.g., Hispanic) are response options on a single question. Participants were classified into age groups ( $<65,65-74,75-84$, and $\geq 85)$. Sex was included.

Enabling Variables-Medicaid eligibility, a proxy measure of socioeconomic status, was determined by inclusion of a state Medicaid identification number on the SOC form. As a proxy measure of social support, participants were classified as living alone or with 
someone. Metropolitan or nonmetropolitan location was included because rural location was found to be associated with less HHC use. ${ }^{21}$

Need Variables-Multiple need variables were chosen as factors that might exert independent influences on Medicare HHC use and to adjust for clinical heterogeneity that might exist across racial and ethnic groups. Diabetes mellitus severity was measured using an OASIS severity rating index for the primary home care diagnosis, ranging from 0 (asymptomatic) to 4 (symptoms poorly controlled, history of rehospitalizations). Presence of depressive symptoms was measured based on a single OASIS item (depressed mood; feeling sad and tearful). Cognitive impairment level was measured using a 5-point OASIS item, ranging from 0 (completely oriented) to 4 (unable to perform cognitive tasks). Dyspnea severity was measured using a 5-point OASIS item (higher score = greater severity). Number of comorbidities was measured by summing the number of recorded secondary ICD-9 codes, up to five. Obesity was based on a single checked or unchecked OASIS item. For urinary incontinence, participants incontinent of urine or requiring indwelling catheterization were considered incontinent. A recorded skin lesion or open wound of any type served as the dichotomous measure of presence of an open wound.

To measure functional disability, 15 OASIS activity of daily living (ADL) and instrumental activity of daily living (IADL) items have response categories arranged in a Likert format from independent (lowest value, 0) to dependent (highest value, 4). The number of response categories varied across items. To adjust for these differences, corrected Likert item scores were constructed by dividing recorded item values by possible maximum item values. Corrected Likert item scores were summed to create ADL and IADL scales. This procedure has been found to be a more-valid disability measurement approach than using recorded item values. ${ }^{25}$

Environmental Variable-U.S. Census region was included to help account for potential effects on service use measures that might result from different geographic distribution of participants from different racial and ethnic groups.

Dependent Variables-Several HHC service use measures were constructed: number of skilled nursing visits per week (99\% of study participants received nurse visits); whether PT was used; for those with one or more PT visits, number of PT visits per week; whether HHA was used; for those with one or more HHA visits, number of HHA visits per week; and number of visits per week from all clinical disciplines combined (nursing, PT, HHA, occupational therapy, speech and language therapy, and medical social work; $<5 \%$ of participants received the latter three services). Visits per week measures, representing service intensity, were chosen to adjust for differences across racial and ethnic groups in HHC episode length.

\section{Analyses}

For the two dichotomous dependent variables (PT use and HHA use), multivariate logistic regression analyses were conducted to determine adjusted odds ratios (AORs) associated with racial and ethnic group membership while controlling for all other independent variables. Dummy variables were created for African Americans, Asians, and Hispanics; whites were the reference category. Dummy variables were also created for other categorical independent variables. Multivariate linear regression analyses were conducted using service intensity measures as continuous dependent variables in separate models. Unstandardized regression coefficients (b) and standard errors were shown as summary statistics. Analyses were conducted using SPSS version 16.0 (SPSS, Inc., Chicago, IL). 


\section{RESULTS}

\section{Sample Characteristics}

As Table 1 shows, $62 \%$ of participants were white, 22\% African American, 12\% Hispanic, and 3\% Asian. Sixty-four percent of study participants were women, and 56\% were aged 75 and older. Hispanics and Asians were most likely to be Medicaid eligible $(P<.001)$. Diabetes mellitus severity index scores indicated that most participants' symptoms were controlled with difficulty and required ongoing monitoring; participants had an average of 2.7 comorbidities. More than one-third of participants had urinary incontinence, nearly $30 \%$ had skin lesions, $22 \%$ were obese, and 22\% were depressed. ADL and IADL scores indicated moderate levels of disability; most participants were cognitively intact. Dyspnea severity scores revealed that, on average, participants were dyspneic with moderate exertion. African Americans and whites were most likely to be obese, Hispanics and whites were most likely to be depressed and have open wounds, and Asians had greatest levels of physical disability. Asians were most concentrated in the northeast, whereas the other groups were most concentrated in the south.

\section{Use of Any PR or HHA Services}

Table 2 summarizes results where proportions of participants receiving PT and HHA services were dependent (column) variables. Thirty-seven percent of participants received PT services; 20\% received HHA services.

Hispanics $(\mathrm{AOR}=0.64,95 \% \mathrm{CI}=0.54-0.75 ; P<.001)$ and African Americans $(\mathrm{AOR}=$ $0.87,95 \% \mathrm{CI}=0.77-0.99 ; P=.03$ ) were less likely than whites to receive PT services. Of predisposing covariates, participants younger than 65 were less likely than those aged 85 and older (reference group) to receive PT services. Of enabling covariates, Medicaid-eligible participants and those living in nonmetropolitan areas were less likely to receive PT services. Of need covariates, greater diabetes mellitus symptom severity and greater cognitive impairment were associated with less likelihood of receiving PT visits, whereas greater number of comorbidities, ADL disability, and IADL disability were associated with greater likelihood of receiving PT services (all $P<.001$ ).

Hispanics were less likely than whites to use HHA services (AOR $=0.72,95 \% \mathrm{CI}=0.58$ $0.88, P=.002$ ). Men and participants younger than 65 were less likely to receive HHA visits than women and participants aged 85 and older; living alone and in nonmetropolitan areas conferred a greater likelihood of receiving HHA visits. Of need covariates, greater cognitive impairment was associated with less likelihood of receiving HHA services, whereas more comorbidities, depressed mood, urinary incontinence, and more functional disability were all associated with greater likelihood of receiving HHA services (all $P<.001$ ). Participants in the northeast and midwest were less likely than those in the south (reference group), and participants in the west were more likely than those in the south to receive HHA services.

\section{Service Intensity Results}

Table 3 displays results where each service intensity measure (visits/week) was a dependent variable: from left to right; nursing, PT, HHA, and all clinical staff combined.

Nursing intensity results revealed that African Americans received fewer nurse visits per week than whites $(\mathrm{b}=-0.273, P<.001)$, and Asians $(\mathrm{b}=0.401, P=.008)$ and Hispanics $(\mathrm{b}=$ $0.197, P=.01$ ) received more. Of enabling covariates, participants in nonmetropolitan areas received fewer nurse visits per week than their metropolitan counterparts. Of need covariates, participants with open wounds received more nurse visits per week, whereas 
those with more comorbidities received fewer. Participants in the midwest and west received fewer nurse visits per week than participants in the south (all $P<.001$ ).

PT intensity results showed that, of participants receiving any PT care, African-American and Hispanic participants received fewer visits per week than whites $(b=-0.093, P=.01$ and $\mathrm{b}=-0.118, P=.03$, respectively). Of predisposing and enabling covariates, the youngest participants received the fewest PT visits per week $(\mathrm{b}=-0.212, P=.001)$, and participants living alone $(\mathrm{b}=-0.116, P=.001)$ or in nonmetropolitan areas $(\mathrm{b}=-0.108, P$ $=.01$ ) received fewer PT visits per week. Of need covariates, greater diabetes mellitus symptom severity and greater cognitive impairment were associated with fewer PT visits per week $(P<.001)$. Participants in the northeast and west received fewer PT visits per week than participants in the south (both $P<.001$ ).

HHA intensity results indicated that, of participants receiving any HHA care, Hispanics received more HHA visits per week than whites $(b=0.511, P<.001)$. Of enabling covariates, participants living alone and Medicaid-eligible participants received more HHA visits per week than their counterparts. Of need covariates, greater ADL disability was associated with more HHA visits per week. Regional comparisons indicate that participants in the northeast received fewer HHA visits per week than participants in the south and that those in the west received more.

All clinical staff intensity results showed that African Americans received fewer visits per week than whites $(b=-0.316, P<.001)$. Nonmetropolitan residence was the covariate most associated with fewer visits per week from all clinical staff, whereas participants with open wounds and those with greater ADL disability received more. Participants in all geographic regions shown in Table 3 received fewer visits per week from all clinical staff than participants in the south.

\section{DISCUSSION}

The purpose of this study was to determine the extent to which racial and ethnic group disparities exist in types and patterns of Medicare HHC services received by beneficiaries with a primary diagnosis of type 2 diabetes mellitus. The Andersen model ${ }^{22}$ was used to delineate covariates that helped account for potential racial and ethnic group heterogeneity and that might be independently associated with $\mathrm{HHC}$ use. Four findings regarding the most statistically significant disparities after covariate adjustment were emphasized. First, African Americans and Hispanics were less likely than whites to receive any PT services, and when they did, they tended to receive fewer PT visits per week than whites. Second, Hispanics were less likely than whites to receive any HHA services, but when they did, they received more HHA visits per week than whites. Third, African Americans received fewer visits per week from nurses and fewer visits per week from all clinical staff combined than whites. Fourth, Asians and Hispanics received more nurse visits per week than whites.

These findings strongly suggest that African-American Medicare HHC beneficiaries with diabetes mellitus receive less skilled nursing and rehabilitation-oriented care than their white counterparts. One possible explanation is that African-American Medicare HHC beneficiaries are less assertive in requesting skilled services, because it is has been shown that African Americans display less assertiveness than whites in their interactions with healthcare providers when faced with the option of receiving cardiac procedures. ${ }^{26,27}$ Another possible explanation is that African-American beneficiaries with diabetes mellitus are more likely to use Medicare $\mathrm{HHC}$ as a personal care-oriented benefit more, because their HHA use patterns were equivalent to whites. 
Disparities were not systematically apparent between Hispanics and Asians; these participants experienced more-intensive nursing care than whites. For Hispanics with diabetes mellitus, the Medicare HHC benefit appears to be primarily a nursing benefit, with less rehabilitation received and less likelihood of receiving HHA services than whites.

Regarding implications of results for Medicare HHC practice, a more-thorough determination of rehabilitation potential in African-American and Hispanic beneficiaries with diabetes mellitus may be in order when comprehensive assessments are conducted during initial home visits to develop a HHC plan. For African-American beneficiaries, once care plans are implemented, HHC clinicians should frequently assess whether nursing care is sufficient to meet the educational and treatment needs of people with diabetes mellitus. Greater cultural competence in addressing these clinical issues by HHC clinicians might help facilitate dialogue with African Americans and Hispanics with diabetes mellitus. ${ }^{28,29}$

Other notable findings worthy of further investigation include, of predisposing variables, participants younger than 65 received less PT and HHA services than participants aged 85 and older; of enabling variables, nonmetropolitan location was associated with lower service use; and participants in the south received the greatest levels of most HHC services.

One other notable result was the high prevalence of Medicaid eligibility in the Asian participant sample (56\%). This high rate contrasts with the relatively low poverty rate of older Asian Americans in the general population. ${ }^{30}$ Asians with diabetes mellitus receiving Medicare HHC may not be at all representative of the general older Asian-American population.

Study limitations are notable. Data reported in this article are from 2002, and it is unclear whether observed patterns would be found with more-recent samples of Medicare HHC beneficiaries. In addition, investigation of disparities was restricted to use of HHC services, and it was not determined whether disparities existed in health-related outcomes. In addition disparities in access to Medicare HHC were not investigated, because this study focused exclusively on beneficiaries who were approved for care under the HHC benefit. The precise diabetes mellitus-related symptoms that prompted the Medicare HHC episode under study cannot be quantified at the beneficiary level. Finally, information was not available on the ethnic or racial background of HHC clinicians conducting beneficiary assessments and constructing care plans.

In conclusion, to the knowledge of the authors, this is the first national investigation of racial and ethnic group patterns of Medicare HHC use for beneficiaries with type 2 diabetes mellitus. This study helps pave the way for further research on how and why Medicarecertified home health agencies design and administer care plans for beneficiaries with diabetes mellitus from different racial and ethnic backgrounds, a topic that has received scant attention in the published literature.

\section{Acknowledgments}

We gratefully acknowledge the expert data management assistance provided by Deborah Paturzo, MS.

Support provided by a grant from the National Institute for Nursing Research (R01 NR005081) to RHF and by a Summer Research grant from the University of Connecticut School of Medicine to AYK.

Sponsor's Role: The sponsors played no role in the design, conduct, or reporting of study results; the conclusions are solely those of the authors. 


\section{References}

1. Vega WA, Rodriguez MA, Gruskin E. Health disparities in the Hispanic population. Epidemiol Rep. 2009; 31:99-112.

2. Heisler M, Smith DM, Hayward RA, et al. Racial disparities in diabetes care processes, outcomes, and treatment intensity. Med Care. 2003; 41:1221-1232. [PubMed: 14583685]

3. Harris MI. Racial and ethnic differences in health care access and health outcomes for adults with type 2 diabetes. Diabetes Care. 2001; 24:454-459. [PubMed: 11289467]

4. Harris MI, Klein R, Cowie CC, et al. Is the risk of diabetic retinopathy greater in non-Hispanic African-Americans and Mexican Americans than in non-Hispanic whites with type 2 diabetes? A U.S. population study. Diabetes Care. 1998; 21:1230-1235. [PubMed: 9702425]

5. Haffner SM, Fong D, Stern MP, et al. Diabetic retinopathy in Mexican Americans and non-Hispanic whites. Diabetes. 1988; 37:878-884. [PubMed: 3384186]

6. Franklin GM, Kahn LB, Baxter J, et al. Sensory neuropathy in noninsulin-dependent diabetes mellitus: The San Luis Valley Diabetes Study. Am J Epidemiol. 1990; 131:633-643. [PubMed: 2316495]

7. Cowie CC, Port FK, Wolfe RA, et al. Disparities in incidence of diabetic end-stage renal disease by race and type of diabetes. N Engl J Med. 1989; 321:1074-1079. [PubMed: 2797067]

8. Haffner SM, Mitchell BD, Pugh JA, et al. Proteinuria in Mexican Americans and non-Hispanic whites with NIDDM. Diabetes Care. 1989; 12:530-536. [PubMed: 2776587]

9. Nelson RG, Morgenstern H, Bennett PH. An epidemic of proteinuria in Pima Indians with type 2 diabetes mellitus. Kidney Int. 1998; 54:2081-2088. [PubMed: 9853273]

10. Resnick HE, Valsania P, Phillips CL. Diabetes mellitus and nontraumatic lower extremity amputation in African-American and white Americans: The National Health and Nutrition Examination Survey Epidemiologic Follow-Up Study, 1971-1992. Arch Intern Med. 1999; 159:2470-2475. [PubMed: 10665896]

11. Lavery LA, van Houtum WH, Ashry HP, et al. Diabetes-related lower-extremity amputations disproportionately affect African Americans and Mexican Americans. South Med J. 1999; 92:593599. [PubMed: 10372853]

12. Karter AJ, Ferrara A, Liu JY, et al. Ethnic disparities in diabetic complications in an uninsured population. JAMA. 2002; 287:2519-2527. [PubMed: 12020332]

13. Chin MH, Zhang JX, Merrell K. Diabetes in the African-American Medicare population. Morbidity, quality of care, and resource utilization. Diabetes Care. 1998; 21:1090-1095. [PubMed: 9653601]

14. Fortinsky RH, Madigan EA, Sheehan TJ, et al. Risk factors for hospitalization among Medicare home care patients. West J Nurs Res. 2006; 28:902-917. [PubMed: 17099104]

15. Davidson MB. Effect of nurse-directed diabetes care in a minority population. Diabetes Care. 2003; 26:2281-2287. [PubMed: 12882849]

16. Hopper SV, Miller JP, Birge C, et al. A randomized study of the impact of home health aides on diabetic control and utilization patterns. Am J Public Health. 1984; 74:600-602. [PubMed: 6721016]

17. Kenney GM. Is access to home health care a problem in rural areas? Am J Public Health. 1993; 83:412-414. [PubMed: 8438982]

18. Kenney GM, Dubay LC. Explaining area variation in the use of medicare home health services. Med Care. 1992; 30:43-57. [PubMed: 1729586]

19. Swan JH, Benjamin AE. Medicare home health utilization as a function of nursing home market factors. Health Serv Res. 1990; 25:479-499. [PubMed: 2199414]

20. Kane RL, Lin W, Blewitt LA. Geographic variation in the use of post-acute care. Health Serv Res. 2002; 37:667-682. [PubMed: 12132600]

21. Schlenker RE, Powell MC, Goodrich GK. Rural-urban home health care differences before the Balanced Budget Act of 1997. J Rural Health. 2002; 18:359-371. [PubMed: 12135156]

22. Andersen RM. Revisiting the behavioral model and access to medical care: Does it matter? J Health Soc Behav. 1995; 36:1-10. [PubMed: 7738325] 
23. Madigan EA, Fortinsky RH. Interrater reliability of the Outcome and Assessment Information Set: Results from the field. Gerontologist. 2004; 44:689-692. [PubMed: 15498844]

24. Tullai-McGuiness S, Madigan EA, Fortinsky RH. Validity testing of the Outcomes and Assessment Information Set (OASIS). Home Health Care Serv Q. 2009; 28:45-57. [PubMed: 19266370]

25. Fortinsky RH, Garcia RI, Sheehan TJ, et al. Measuring disability in medicare home care patientsapplication of Rasch modeling to the Outcome and Assessment Information Set. Med Care. 2003; 41:601-615. [PubMed: 12719685]

26. Maynard C, Fisher LD, Passamani ER, et al. Blacks in the Coronary Artery Surgery Study (CASS): Race and clinical decision making. Am J Public Health. 1986; 76:1446-1448. [PubMed: 3490796]

27. Woodard LD, Hernandez MT, Lees E, et al. Racial differences in attitudes regarding cardiovascular disease prevention and treatment: A qualitative study. Patient Educ Couns. 2005; 57:225-231. [PubMed: 15911197]

28. Gavin JR III, Wright EE Jr. Building cultural competency for improved diabetes care: African Americans and diabetes. J Fam Pract. 2007; 56(9 Suppl Building):S14-S20. [PubMed: 18671923]

29. Caballero AE, Tenzer P. Building cultural competency for improved diabetes care: Latino Americans and diabetes. J Fam Pract. 2007; 56(9 Suppl Building):S21-S30. [PubMed: 18667140]

30. Yeo G. How will the U.S. health care system meet the challenge of the ethno-geriatric imperative? J Am Geriatr Soc. 2009; 57:1278-1285. [PubMed: 19558479] 







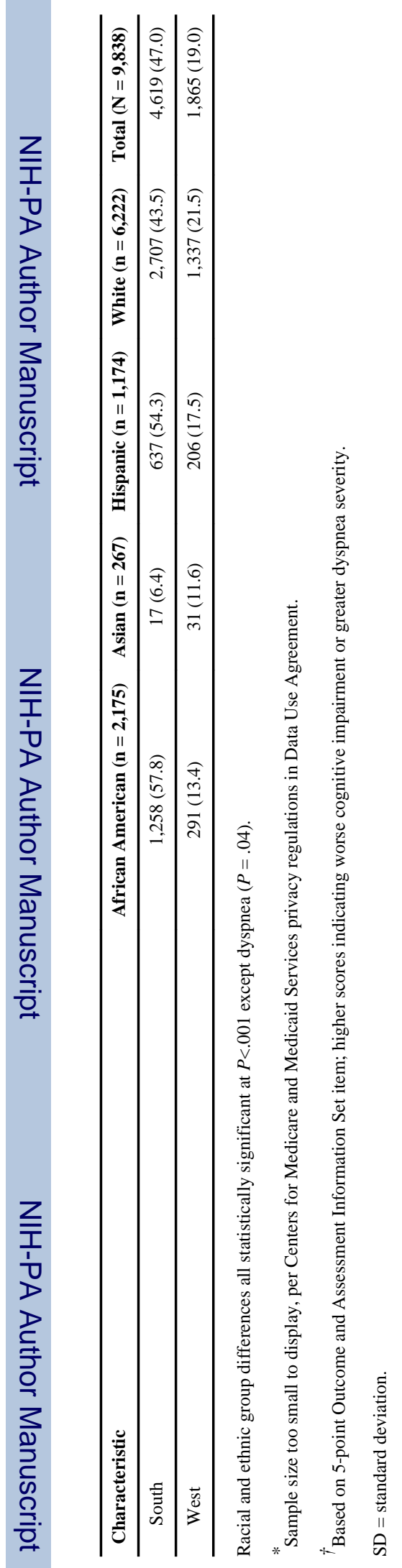


Table 2

Logistic Regression Analyses with Physical Therapy and Home Health Aide Visits as Dependent Variables

\begin{tabular}{|c|c|c|c|c|}
\hline \multirow[b]{2}{*}{ Independent Variable } & \multicolumn{4}{|c|}{ Adjusted Odds Ratio (95\% Confidence Interval) $P$-Value } \\
\hline & \multicolumn{2}{|c|}{$\begin{array}{l}\text { Physical Therapy Visits } \\
\text { N }=9,168\end{array}$} & \multicolumn{2}{|c|}{$\begin{array}{l}\text { Home Health Aide Visits } \\
\text { N = 9,168 }\end{array}$} \\
\hline \multicolumn{5}{|l|}{ Predisposing characteristics } \\
\hline African American & $0.873(0.774-0.985)$ & .03 & $1.110(0.964-1.278)$ & .18 \\
\hline Asian & $0.771(0.569-1.045)$ & .09 & $0.682(0.440-1.057)$ & .09 \\
\hline Hispanic & $0.640(0.543-0.754)$ & $<.001$ & $0.716(0.582-0.880)$ & .002 \\
\hline Male & $1.009(0.914-1.115)$ & .85 & $0.810(0.716-0.916)$ & .001 \\
\hline \multicolumn{5}{|l|}{ Age } \\
\hline$<65$ & $0.672(0.554-0.815)$ & $<.001$ & $0.505(0.396-0.644)$ & $<.001$ \\
\hline $65-74$ & $0.878(0.757-1.018)$ & .08 & $0.797(0.672-0.947)$ & .01 \\
\hline $75-84$ & $1.015(0.886-1.162)$ & .83 & $0.958(0.821-1.117)$ & .58 \\
\hline \multicolumn{5}{|l|}{ Enabling characteristics } \\
\hline Living alone & $1.084(0.975-1.205)$ & .14 & $1.748(1.537-1.987)$ & $<.001$ \\
\hline Medicaid eligible & $0.669(0.589-0.758)$ & $<.001$ & $0.851(0.733-0.989)$ & .03 \\
\hline Nonmetropolitan residence & $0.599(0.525-0.682)$ & $<.001$ & $1.345(1.167-1.550)$ & $<.001$ \\
\hline \multicolumn{5}{|l|}{ Need characteristics } \\
\hline Diabetes mellitus severity & $0.845(0.785-0.910)$ & $<.001$ & $0.973(0.892-1.062)$ & .54 \\
\hline Number of comorbidities & $1.334(1.290-1.379)$ & $<.001$ & $1.170(1.124-1.217)$ & $<.001$ \\
\hline High risk of obesity & $1.034(0.922-1.159)$ & .57 & $1.119(0.980-1.279)$ & .10 \\
\hline Depressed mood & $1.119(1.001-1.251)$ & .047 & $1.254(1.102-1.425)$ & .001 \\
\hline Cognitive impairment & $0.754(0.708-0.802)$ & $<.001$ & $0.883(0.823-0.947)$ & $<.001$ \\
\hline Short of breath & $0.953(0.913-0.995)$ & .03 & $1.061(1.009-1.115)$ & .02 \\
\hline Open wounds & $1.083(0.977-1.201)$ & .13 & $1.159(1.027-1.308)$ & .02 \\
\hline Urinary incontinence & $1.082(0.974-1.203)$ & .14 & $1.251(1.107-1.413)$ & $<.001$ \\
\hline Activity of daily living index & $1.325(1.268-1.384)$ & $<.001$ & $1.482(1.409-1.558)$ & $<.001$ \\
\hline Instrumental activity of daily living index & $1.192(1.136-1.251)$ & $<.001$ & $1.108(1.043-1.177)$ & .001 \\
\hline \multicolumn{5}{|l|}{ Geographic region } \\
\hline Northeast & $0.898(0.771-1.044)$ & .16 & $0.597(0.491-0.725)$ & $<.001$ \\
\hline Midwest & $1.038(0.918-1.174)$ & .55 & $0.771(0.663-0.896)$ & .001 \\
\hline West & $0.990(0.869-1.128)$ & .88 & $1.197(1.027-1.396)$ & .02 \\
\hline
\end{tabular}




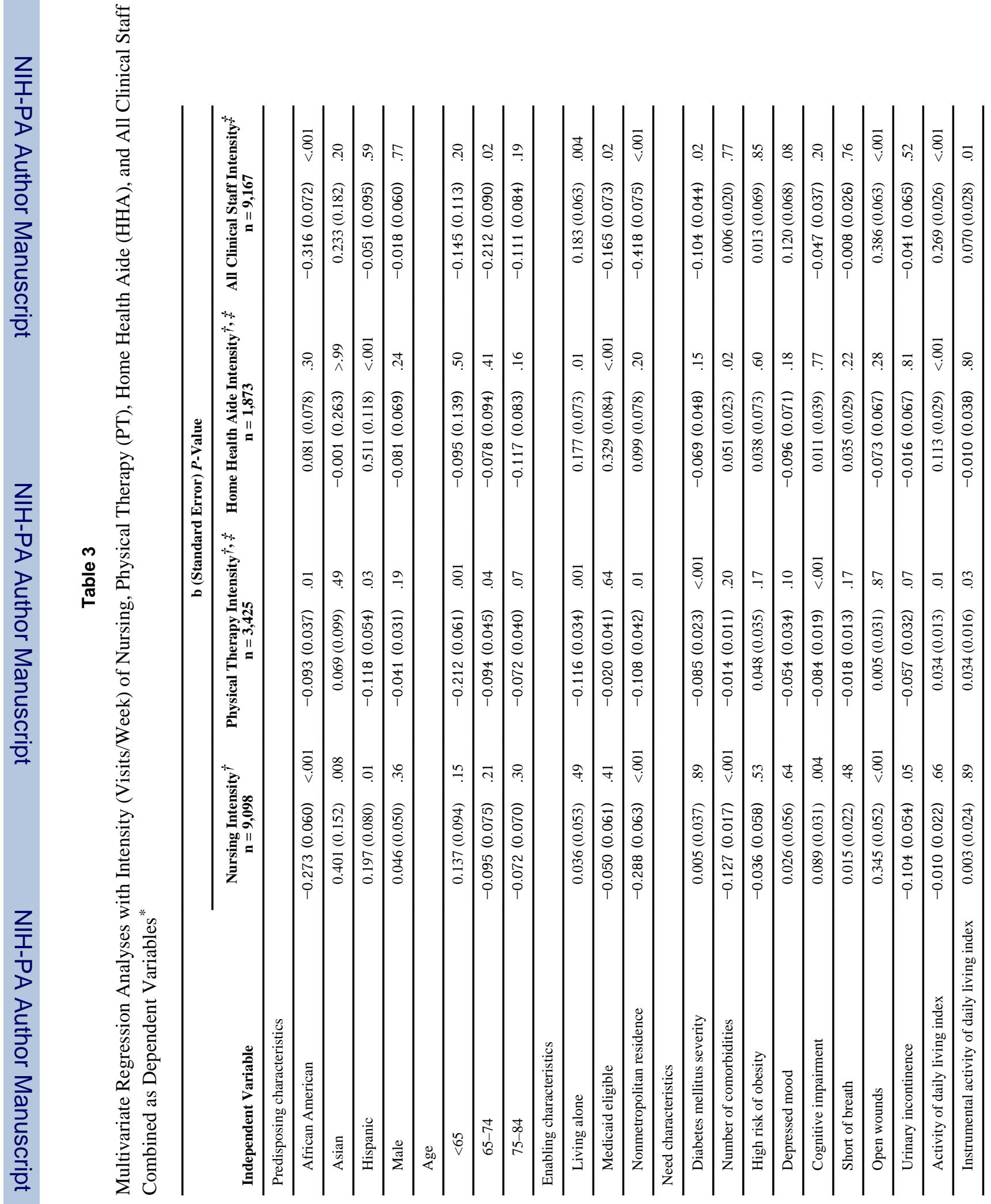




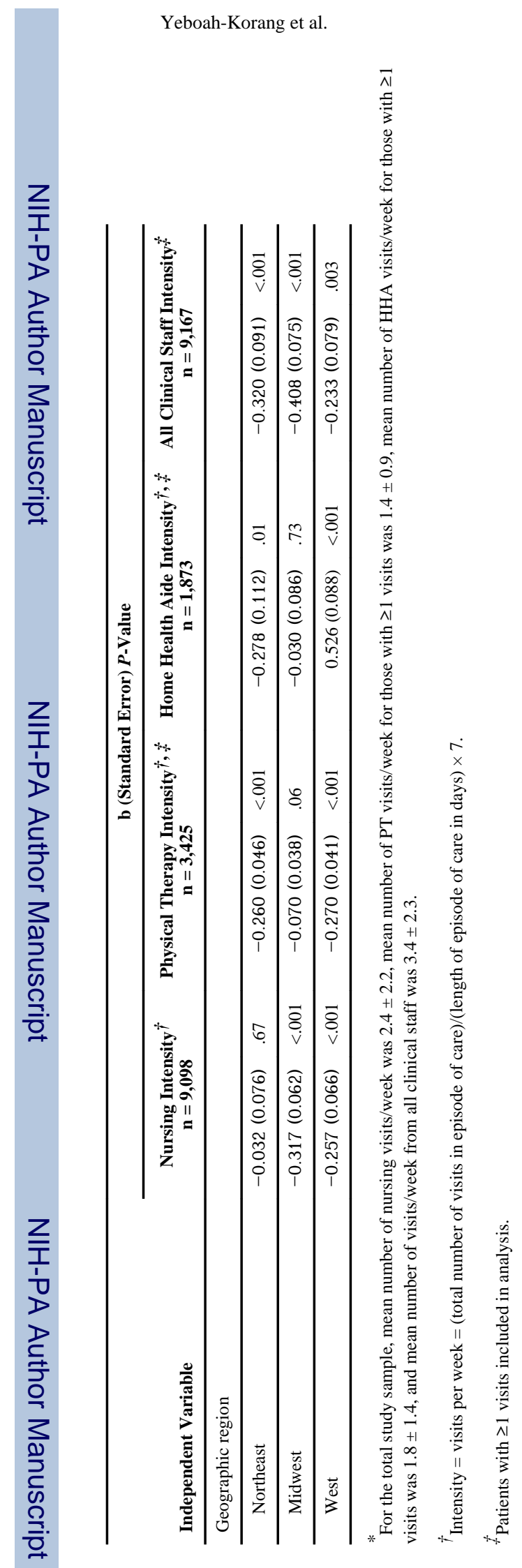

J Am Geriatr Soc. Author manuscript; available in PMC 2011 July 10. 